\title{
Using Green Infrastructure in Urban SITES for Sustaining Groundwater in Iraq
}

\author{
Zaynab R. Abaas
}

\begin{abstract}
The aim of This research comes to create a sustainable urban use of the hydrological resources in Iraq. It is comes from the idea of resolving the mass movement problems in Iraq resulting from urbanization, weathering process, soil nature and groundwater pressure, by using new type of green energy investment using groundwater within a new term called Best Management Practices (BMP's) to reach the sustainable urban sites through green infrastructure processes. The most important finding of this research is the possibility of converting the urban damages caused by groundwater into useful green clean energy at these sites with the ensuring of sustaining use for the hydrogeological resources.
\end{abstract}

Index Terms-Green infrastructure, sustainability, groundwater, urban sites.

\section{INTRODUCTION}

Sudden and rapid changes in the urban system of the cities and increasing human activities, lead to huge exhaustion to the Geo-morphological, Ecological, and Biological cycles in addition to unfavorable consequences related to all of the global ecosystem services that depend on the Ecological functions' health. This indirect impact leads to grand losses in catchment areas protection, endanger the safety of the earth and increased erosion. Moreover, it enhance the disappearance of biodiversity, and the deterioration of local and regional air quality aside from the increase of geo-environmental hazards that differs (increasingly or decreasingly) depending on a group of factors, varied from the economic and social factors to the natural and spatial ones. All that led to increase the specialists' interests trying to balance between preserving and protecting environmental and earth resources from damages from one hand, and meet the requirements and needs of modern human being on the others. Until the coming of sustainable development with all its social, economic and environmental dimensions and evolving rapidly in order to achieve the maximum efficiency of protecting the environment and natural biodiversity, improving the infrastructure and the superstructure of the urban environment and supporting the humanity and communities by investing the clean green energies to gain a sustainable healthy urban development.

Manuscript received December 26, 2012; revised February 1, 2013.

Zaynab R. Abaas is with Instructor in the Baghdad Univ., Iraq (email: z_swanlake@yahoo.com).

\section{MASS MOVEMENT HAZARDS}

Among the most prominent Geo-environmental Hazards are Mass Movement hazards which result from having large quantities of water in the soil by rain or high groundwater level. While Mass Movement hazards include free falls as the mass material, whether it was rock or mud, has a little contact with the land underneath, they are in many forms depends upon the material component of the soil, and the extent of the human and natural operations contribute to the comprehension and support strength [1]. This fall is impacted by many factors the most important of which are: geological nature of the earth, type of the soil, inclination degree, topographical structure of the soil, climate, vegetation, water (irrigation), time, and human activities [2]. In other words, mass movement happens in many forms, the most important of which; Slumps, Slides, Falls, Flows, and Subsidence, Fig. 1 [3].

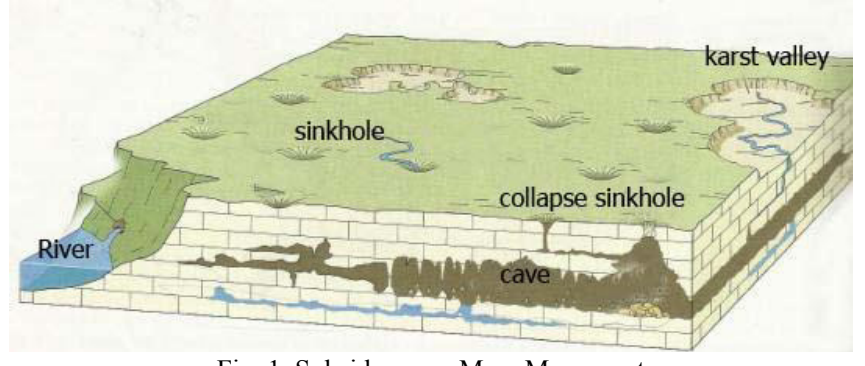

Fig. 1. Subsidence as Mass Movement

Subsidence considered the most mass movement to be studies for their heavy existence in Iraq [4]. Although, it is a complicated, slowly to be formed and takes years and decades, they are quick in happening and in influencing. Their emergence happens within Karst areas as an indicator of the primary hazard of settling and they are the warning of bigger hazards in the way of approaching the Sinkholes that suddenly swallow the earth. All this happen without any prelude of any kind of danger. Water quantities in the soil is deemed the basic reason behind the Subsidence, its types are dependents on the geological structure of the soil. However, water infiltrated from surface of the earth as a result of human activities like irrigation or having some default in the water or sewage nets, or natural causes such as rain in winter or the underground water in the beneath layers of the soil have negative impact on the Alluvial soil (the mixture of sandy mud), or the rocky (gypsum or limestone), where it is mixed with the mud component to produce fluid mix loses the original soil from its characteristics and its strength [5]. Like what we witness on the riverbanks in the sedimentary areas of Iraq and especially in Baghdad [6]. Furthermore, some of earth layers are built of minerals that have the ability to react with water and the swelling capacity 
what leads to the Karsts (such as Montmorillonite minerals which increase greatly in volume when they absorbs water.) exists within the mud of Iraq especially in the western part of it and in Baghdad [7].

From the foregoing, we understand that one of the pressures directed on the earth system is the underground natural environment. Such pressures are emerged from the natural underground waters or the pressure of the urban system and the surface environment, its impact is reflected over time on the environmental safety. Although Iraq is one of these areas subject to the of mass movement hazard as shown in Fig. 2, there is no clear planning vision is available for such hazards due to the fact that the governmental institutions and offices do not take the hazards of mass movement into consideration and do not consider it as an importance to be observed in the planning operations and urban projects. We therefore must investigate for the most important modern treatments adopted to preserve the environment and earth from one side and to exploit it in a way that leads to the sustainability of the urban environment.

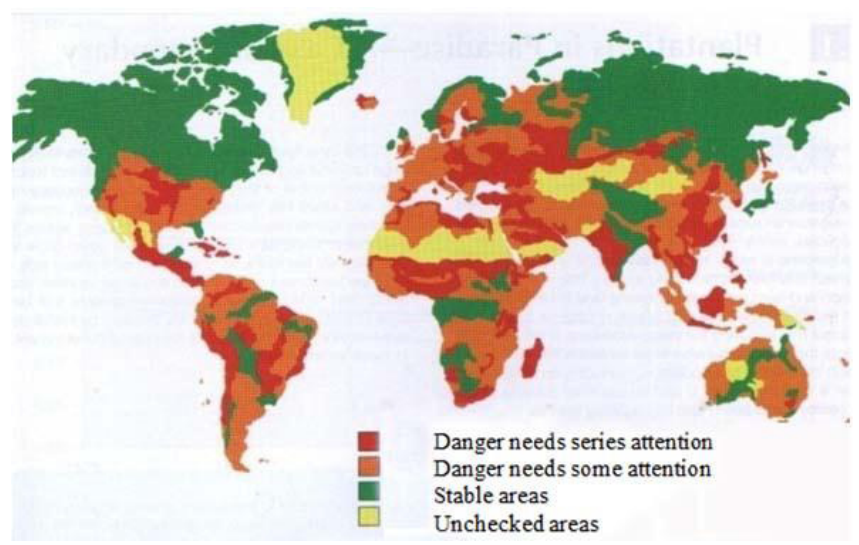

Fig. 2. Mass Movement hazard around the world showing the series need for concern and solutions in Iraq

\section{GeO-HydrologicAl CARACTERISTICS OF BAGHDAD CITY}

Baghdad City is located in the central alluvial plain of Mesopotamia, and this area newly emerged and its age is around 10 thousand years, the human agricultural and constructional activity affected the formation of its soil and made rapid changes in the soil of one area that is different from another that is very close to it and it is because of the following: tapping projects drilled in the form of channels, the course of the Tigris River is changed from time to time, and the river flooding year after year [8]. In spite of the hazard of the mass moving witnessed by Baghdad City because of its location near the rivers banks and for the alluvial type of the soil, the type of the human activities, but such hazards are slowly emerging, sudden in happening, strong in harming, but their harm is accumulative over time, therefore we see that it is possible and would be achieved actively through an initiative to be made to make an analytical studies for the nature of the soil, its characteristics and it impact on the urban structure from one side and to know the type and quality of the underground water in another. It is possible to reach to a new type of solutions that could lessen the damage happen to the urban environment and at the same time make use of the underground water energy in producing sustainable green energy by using the green infrastructure that is prevailing increasingly nowadays in the advanced countries in the aim of preserving waters and recycling them [9].

\section{GREEN- INFRASTRUCTURE}

It is a mixture of administrative and technological applications that uses, consolidate, and imitates the natural water cycle by: absorption, infiltration, evaporation, transpiration and re-use of the recycled water. Such treatments started for the purposes of forestation campaigns, re-vegetation, maintaining the green borders, and they increased and became modern patterns that could be used in any type of soils and in various treatment methods within the urban environment that are built to solve the environmental, Geo-hydrological, and planning problems, Added to the concentration on the economic benefits achieved from recollecting and reusing the water for the purposes of irrigation, inside bathrooms within what is known as the grey water. Or by keeping all forms of water away from the health sewage networks, reducing the runoff melted snow and preventing them from eroded the soil, in other words they are flexible and completely controllable and easy go with the site factors of the chosen project. To be more accurate, the main purpose of the green infrastructure is to retain the water balance in a similar way to the natural [10].

While from the planning point of view, green infrastructure could be achieved in many levels: at site, housing blocks, regional, or through project related to the maintenance of the traditional infrastructures [11]. The basic idea of these techniques depends on: the increase of the infiltration surfaces that are able to absorb the water by ways of filling and redeveloping them using the idea of ecological trace, calculating the amount of the penetration surfaces compared to the non-penetration surfaces such as vehicle parks, roads, pavements, and walkways that add an additional load on the natural environment alongside with the humanitarian activities and urban buildings. This could be achieved by designing an underground network of concrete pipes and pools to be linked to an upper network of a vegetation designed within the natural or industrial environments that allow water penetration to the soil to solve some problems or to collect water that is to be transported within its networks to make practical use of it or to get rid of it (drainage). However, green infrastructure started by using Green roofs, rain gardens, pocket wetlands, re-vegetation and reforestation, then it developed to include vegetated swales, permeable pavements, vegetated median strips filters \& strips, Bio Retention Berms and Retentive Grading, Bio Swales Pond ....ext, as shown in Fig. 3 [12].

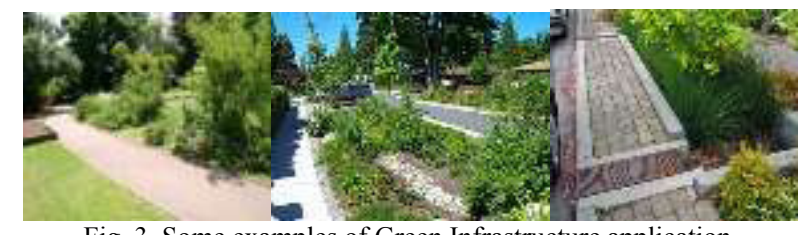

Fig. 3. Some examples of Green Infrastructure application. 


\section{BAGHDAD University Housing COMPleX AS A CASE STUDY}

\section{A. Location of the Study Area}

The study area is within the borders of Baghdad University, which is in the southern part of Baghdad the capital of Iraq, to the east of Tigris on Al Risafa Side, within an urban fabric of Al Karradah [13] as shown in Fig. 4. Housing complex, which built to the faculty, was constructed in the university. This project started with a small housing project considered as the nucleus core of a large housing project started in (2008) and the first phase of it finished in 2010 by building three housing buildings, with 3 floors each. This project was followed by a proposal of a design to construct a housing compound with multi stories buildings ( $8-12$ floors) to be made by the engineering consular office at Baghdad University, and suppose to finish by 2015 [14] .

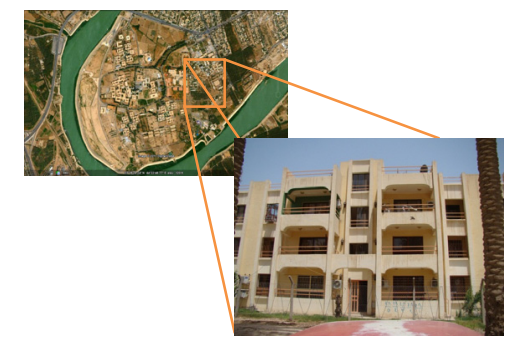

Fig. 4. The study area (the faculty housing complex) within the borders of Baghdad University

\section{B. Geology of the Study Area}

The soil of Baghdad city in particular and the Mesopotamia in general are characterized by alluvial soil with multi-layers; mud river sediments, sand, and silts. The geological studies made for the soil of Baghdad University shows four ranges having great impact on the constructed teaching buildings; they are to be kept in mind when designing any future urban structure [15], see Fig. 5 showing the earth layers in Al Jadriya area.

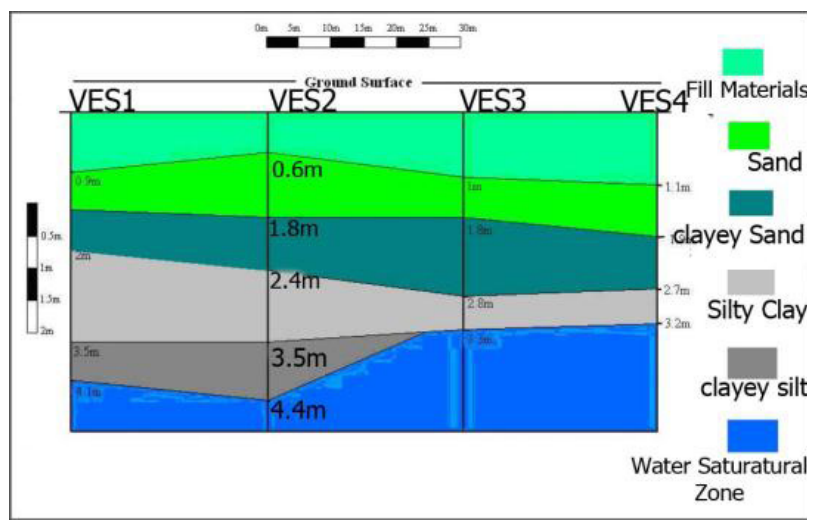

Fig. 5. The earth layers in Al Jadriya area

The geological ranges in Al Jadriya in particular are illustrated as follows:

The first layer: Non-cohesive Silt clay or clayey silt and sand, the layer thickness ranges between (0.7-2.8 meters), sedimentations of the water in the sewages.

The second layer: it is represented by non -continuous clay lenses and silt clay lenses, and it is the most important range, it revealed the causes behind cracks and crashed happen to the structures of the university buildings, as well as the recurrent incidents of housing areas collapses incidents in Al Karradah that amounted in 2011 to (53 collapses) as shown in Fig. 6 [16].
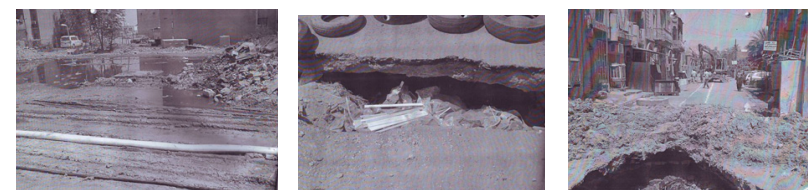

Fig. 6. Some karsts and collapses in Al Karradah (the boundary of the study area).

The third layer: it represents Brown to Gray sand, it is a deeper layer unsaturated groundwater despite the fact that its thickness is around (2-7.2 meters) with mud or slimy lenses now and then.

The fourth layer represents the confined underground water that able to be invested in the area of study, it appears after the settlement of the sand layers on the mud layers, and Started after more than 25 meters. [17]

\section{Hydrology of the Study Area and Its Problem}

The geophysical studies proved highness of underground water in some certain areas of Al Karradah, while its levels were lower in other areas, and what complicated the problem is the flow of the water strain goes towards the teaching buildings of Baghdad university because of the higher level of the water compared with the level of the river water of Tigris, as shown in Fig. 7. While some years before, the flow of this water, and because of the height of the Tigris water, to the north and toward the opposite side. This would suggest some future karsts for the ability of the water reaction with the sand and mud alluvial soil, and the probability of sink formation over time, [18]. Here, and after asking the spicialists, there is a posibility of draw the groundwater and recycle it by using it as a clean energy which is capable of gaining the self efficiency of water, electricity and cooling - heating system in the housing complex.

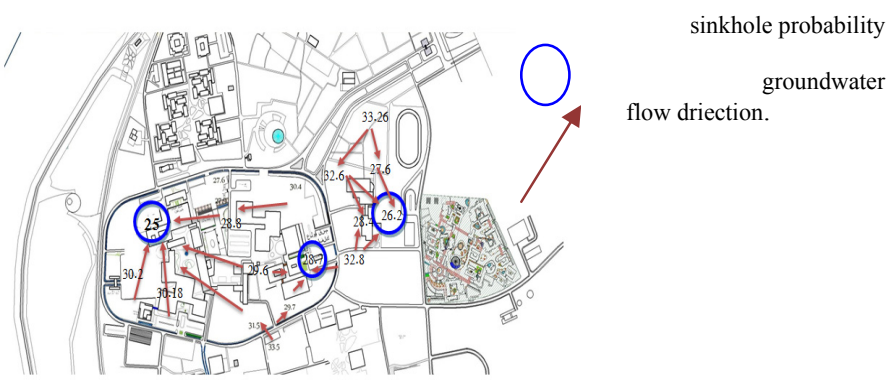

Fig. 7. The direction of groundwater flow and levels in the University and the sinkhole probability.

\section{Sustainable Solutions and Strategies}

After addressing the geological and hydrological risk faced by the city of Baghdad in general and the case study particularly, it became possible to develop a number of solutions and viable strategies for the purposes of development of the study area to a sustainable residential project by investing groundwater's energy and using green infrastructure, which its foundations have been applied on the basis of a constructed of urban environment

The process is made by connecting all parts of the 
projects from the first stage of designing with a network of underground concrete basins starting with the wells which is located about (1 kilometer) from the site of the housing complex, and this network has different pipelines that are isolated from soil by using glass and asphalt to prevent the erosion of its parts down the corridors and walkways and then a Tank will be built in the corner closest to the wells (which is suggested the located to be in the southwestern part of the site), and in ten meters height to facilitate the performance of systems of irrigation as well as treatment unit of gray water and which contain rooms for employees and supervisors that oversee the successful functioning of the system. However, the establishment of supplements and details of green infrastructure in order to optimize the drawn groundwater, as the process is done by:

First: Establishing waterways within sidewalks and in a width of no more than $(40 \mathrm{~cm})$, where it works primarily on the delivery of water to the trees planted on both sides of the pavement and create a climatic environment through softening the atmosphere, this as well as being a landscape that add a touch of design to the residential area that make residents interact with the natural environment and develop their sense of sense of responsibility towards the land and the area to which they belong. As Shown in Fig. 8.

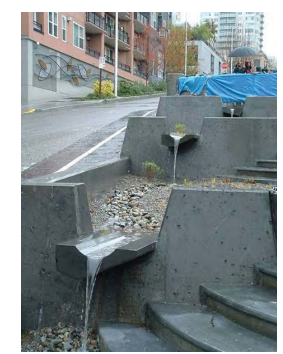

Fig. 8. Waterway as green infrastructure.

Second: Establishing plantings basins and boxes surrounding a residential building that works to ensure the continuous watering of plants and gardens proposed and originally existing on the one hand, and working to improve the atmosphere and increase community interaction with the green environment on the other hand. There are two types of plantings basins and boxes: Type 1, where the green infrastructure network is passed under the plantings basins by providing those basins from below with pipes that feed the plants and supply the proposed heating and cooling systems with water needed, and other linked to gray water network and processing unit and the replenishment that are linked with all parts of the project as stated previously. As for the second type, it is the green infrastructure network is linked to the ground directly, as the watering gardens surplus is returned from irrigation operations to the basins again through perforated pipes designed at the bottom of the gardens, thus contributing to an increase geo-environmental interactions and as noted in Fig. 9 [19].

Third: Establishing and vegetating median strips permeable pavements in children's play areas and large spaces like parking lots for vehicles, tennis courts and football fields. this idea is not much different from the idea of plantings basins regarding the ensuring of the permeation of water through it and the possibility of environmental venting of the land, but it is not required in the establishment of its pipelines the existence of a link with buildings and housing units, they are often linked with the ground, where it contains one type of pipelines which receives water upon cleaning operations or during rain, and the rest of it is sent to the ground insuring the continuity of groundwater.

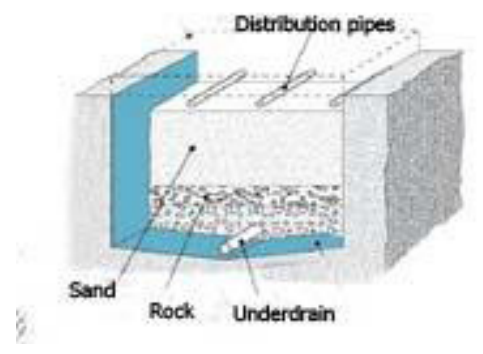

Fig. 9. Types of green infrastructure

We can apply both types of planting boxes in the area of study and bring groundwater to the complex as shown in Fig. 10 .
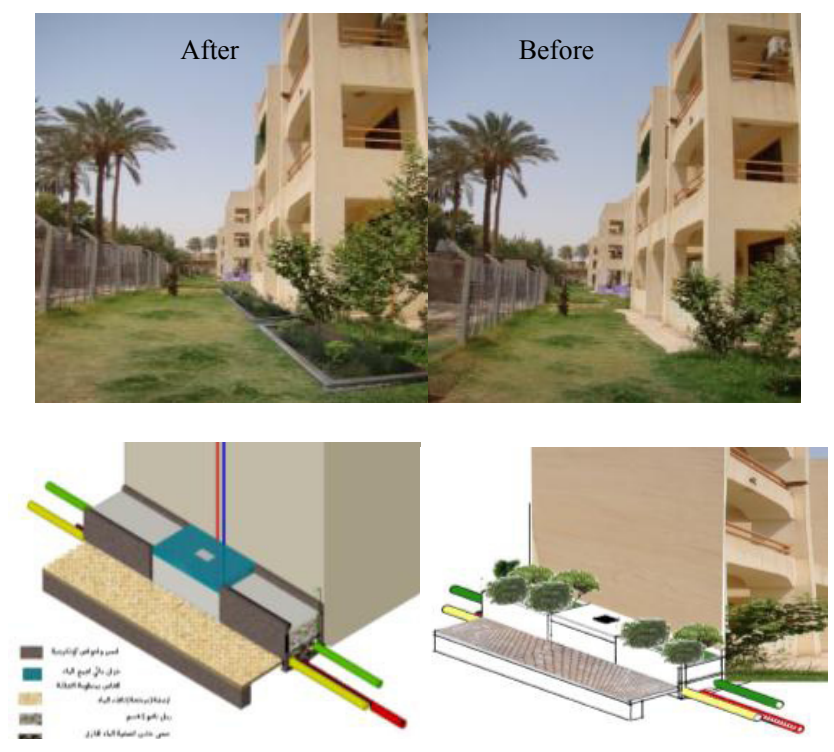

Fig. 10. Developing the housing complex using green infrastructure

Fourth: Water filtration pavements and Subsurface Infiltration: Include the transfer of what can be transformed of unfiltered spaces of pavements, and walkways into penetrating areas by using building and construction materials that have the ability to solar radiation and high water permeability after upgrading the quality of surfacing materials and converted it from unfiltered water pavements and roads into types that have the ability to filter it in the housing complex, in order to help to stimulate the process of evaporation and to soften the atmosphere, as shown in Fig. 11, like yellow brick or cornice stone. That what has been said of the previous types of pavements and roads have proved their efficiency in the survival and continued interaction of soil with the atmosphere and the surrounding environment and in the form which can be considered a harmless and environmentally friendly open spaces.

Fifth: That what has been mentioned above is a simplified application of the idea (green infrastructure) and ways to take advantage of them as a means to simulate nature. As for the establishment of heating - cooling systems 
that rely on groundwater drawn from wells, which move through the proposed Green infrastructure pipelines, and which proved its purity and lack of its water to the filtering process and reduce the salinity - as mentioned earlier depends on the solar cells systems in all its operations and filtration to purify water withdrawn, and then re-injected into the pipeline system to heating, cooling, and thus reduce the consumption of electric power, as noted in Fig. 12 as an example.

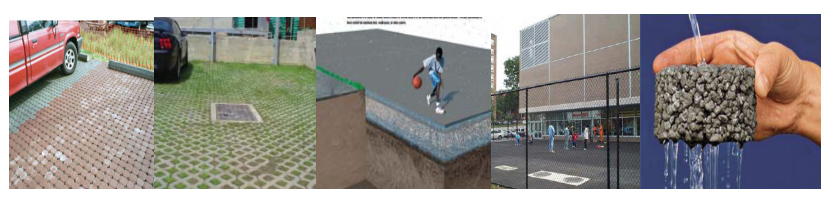

Fig. 11. Types of water filtration pavements.
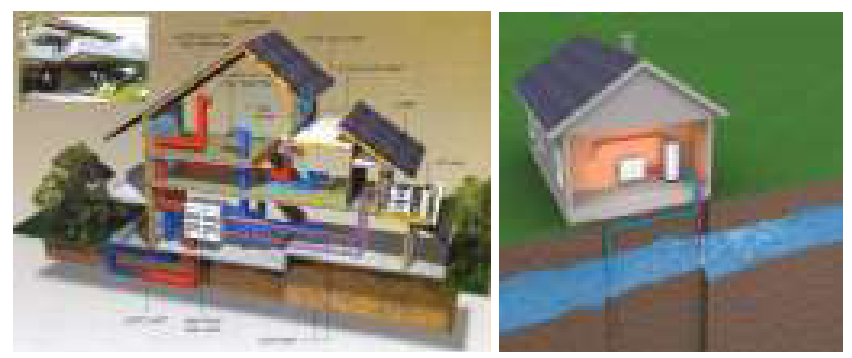

Fig. 12. Using groundwater as green clean energy at housing

Sixth: Design a system for the supplying and pumping water through the pipeline of the green infrastructure network by separate pipeline directly linked with the residential complex's bathrooms for the use of this water like gray water, and by depending on the solar cells that operate as an electric generator, which is an experience highly effective, that has been adopted today in the modern housing projects, and it is recommend strongly to reduce the consumption of pure water, where an individual consumed per capita between $(30-45 \%)$ of pure and drinking water for the purpose of watering gardens and baths.

\section{FINDINGS AND RECOMMENDATIONS}

In conclusion, there is great effectiveness of studying Hydro-geological resources and Geo-environmental Hazards to reach the sustainable urban sites, Not only in the sensitive areas but also these studies became important components for developing Best Management Practices' applications (BMP's) and sustainable urban growth.

Moreover, studying Hydrogeological resources expand the choices in front of the urban planner to adopt a lot of planning's alternatives and green treatments (like using Green infrastructure), which exploit the clean earth energy and protect the environment in accordance to unavailable formations and techniques in the absence of those components.

Thus, we highly recommend studying and exploiting the renewable earth unused resources like Hydrogeological resources which are abounded in our Arabic countries, as much as the solar power resources, associated with the universal trends toward ecological, clean, urban future.

\section{REFERENCES}

[1] C. W. Montgomery, Environmental Geology, 8th ed. McGraw Hill Higher Education, pp. 183, 2008.

[2] E. A. Keller, Introduction to Environmental Geology, upper Saddle River, New Jersey: Pearson Prentice Hall, pp. 242, 2005.

[3] C. W. Montgomery, Environmental Geology, 8th ed. McGraw Hill Higher Education, pp. 183, 2008.

[4] V. Sissakian and H. Al-Mousawi, "Karstification and related problems examples from Iraq," Iraqi Bulletin of Geology and Mining, vol. 3, no. 2, pp. 11-12, 2007.

[5] E. A. Keller, Introduction to Environmental Geology, upper Saddle River, New Jersey: Pearson Prentice Hall, pp. 249-260, 2005.

[6] V. Sissakian and H. Al-Mousawi, "Karstification and related problems examples from Iraq," Iraqi Bulletin of Geology and Mining, vol.3, no. 2, pp. 4-5, 2007.

[7] K. Al- Bassam, "Swelling soils in the west desert and its effection on construction," in 1st Michanice of Soil and Foundation Engineering Conf. Baghdad- Iraq, pp.1-30, 1993.

[8] T. K. Hattab, The Study of Baghdad's Soil Proprieties, Ministry of housing and construction Publising, Baghdad, Iraq, pp.14-25, 1986.

[9] Z. R. Abaas, "The role of environmental geology and green infrastructure in reaching the sustainability of urban sites," Ph.D. Dissertation, Institute of Urban and Regional Planning, Baghdad Univ., Baghdad, Iraq, 2012.

[10] Stormwater Management Guidance Manual, Philadelphia Water Department publising, City of Philadelphia, pp. 529, 2010.

[11] Z. R. Abaas, "Diverse approaches to achieve the Sustainable Urban Form, The Holy Najaf as a case study," presented at the 3rd joint planning conference,Duhok, Iraq, 30-2 Sept., 2012.

[12] Stormwater Management Guidance Manual, Philadelphia Water Department publising, City of Philadelphia, pp. 89-200, 2010.

[13] H. F. Saeed, "GPR Method and its Engineering Application in Baghdad University Site," M.S. dissertation, Dept. Geology, Sc., Baghdad Univ., Iraq, 2010.

[14] Master design of Baghdad University, Engineering Consular Office, Baghdad Univ. publishing, pp.112, 2009.

[15] M. Al-Awssy, "The study of sediments using Electric Resistivity Method," M.S. dissertation, Dept. Geology, Sc., Baghdad Univ., Iraq, 2004.

[16] Al-Karrada Karsts Reports, Sewage directorate, Baghdad municipality, 2011.

[17] H. F. Saeed, "GPR Method and its Engineering Application in Baghdad University Site," M.S. dissertation, Dept. Geology, Sc., Baghdad Univ., Iraq, 2010.

[18] M., Al-Awssy, "The study of sediments using Electric Resistivity Method,” M.S. dissertation, Dept. Geology, Sc., Baghdad Univ., Iraq, 2004.

[19] Stormwater Management Guidance Manual, Philadelphia Water Department publising, City of Philadelphia, pp. 119, 2010.

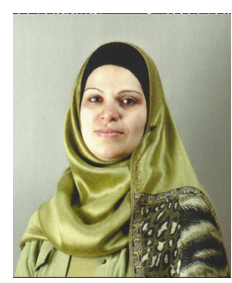

Zaynab Radi Abaas Abid was born on March 4, 1975 in Iraq. She has been working as a faculty member in the Architectural Engineering Dept. University of Baghdad since 2002, graduated from the same department in1997. After a while, she took her master degree in urban studies from the Higher Institute of Urban \& Regional Planning, University of Baghdad, 2000. Her PhD from the same institute "the Higher Institute of Urban \& Regional Planning, University of Baghdad" with a research scholarship at the United State of America at MIT for one academic year. She developed her own small business; she designed many houses using AutoCAD, 3d MAX and V-ray programs, and built more than 14 one (as an advisor and designer). She is good at using GIS program and SPSS. 